\title{
Distraktionsrahmen für die Marknagelung
}

Dankward Höntzsch
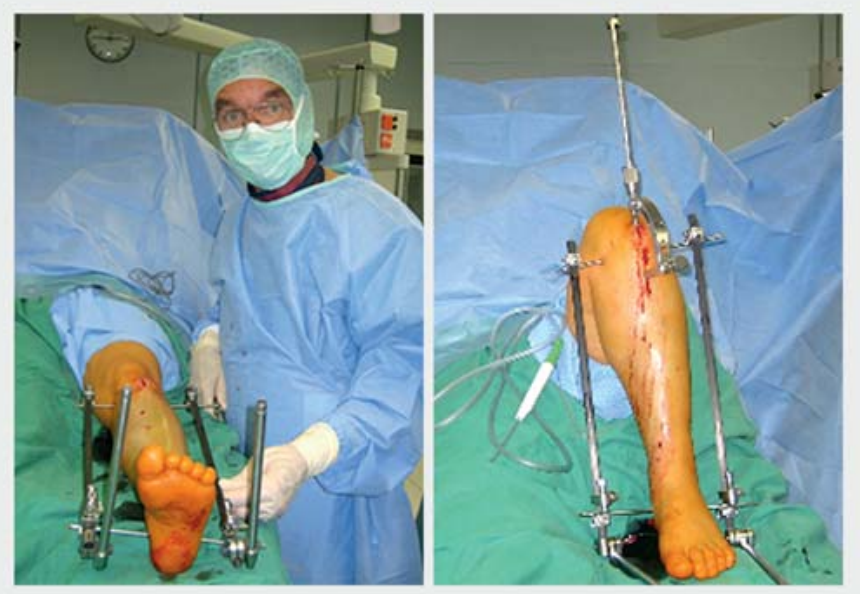

- Abb. 1 Distraktionsrahmen, links bei gestrecktem, rechts bei gebeugtem Kniegelenk.

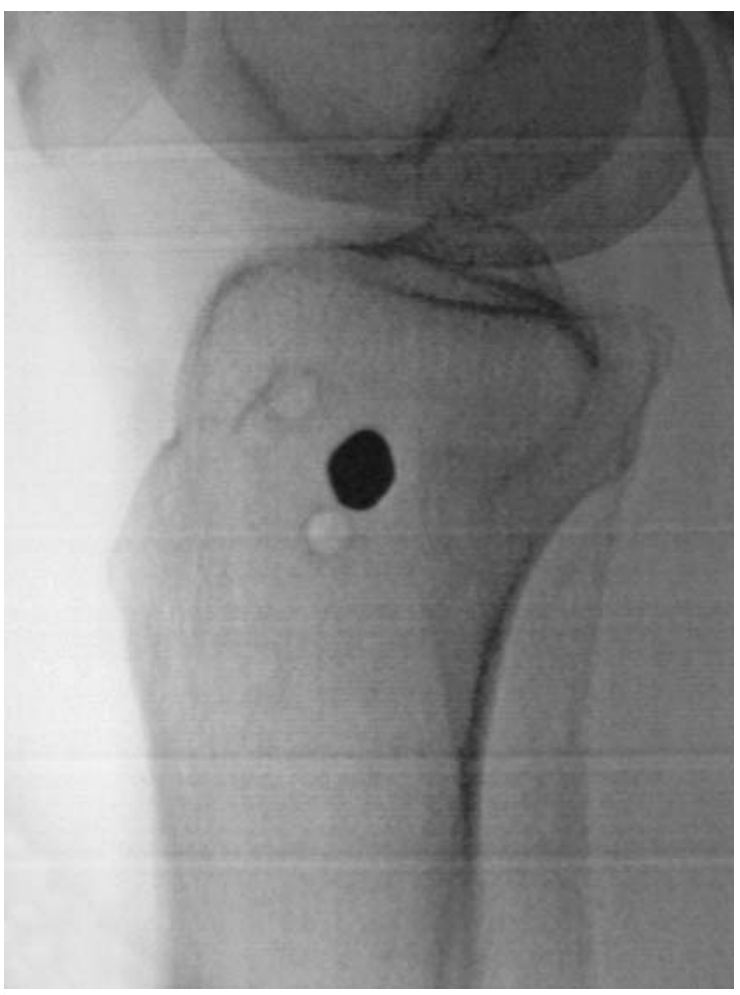

- Abb. 2 Steinmannnagel am Tibiakopf in der sicheren Zone vor dem Fibulaköpfchen, aber außerhalb des Raumes für den Nagel.
Bei schwierigen, aber auch einfachen Marknagelungen bewährt sich ein Distraktionsrahmen: In diesem Distraktionsrahmen kann das Bein im Kniegelenk gestreckt und maximal gebeugt werden. Die Distraktion reponiert und schafft Ruhe. Wenn an den Distraktionsrahmen distal noch 30-50 nach vorne zeigende Rohre angeschraubt werden, kann das Bein für die Operation sogar hingestellt werden ( $\bullet$ Abb. 1).

Anwendung:

Am Tibiakopf wird proximal dorsal vor dem Fibulaköpfchen, d. h. in einer sicheren Zone, aber außerhalb der Einflugschneise des Nagels ( $\triangleright$ Abb. 2), ein Steinmann-Nagel und im Kalkaneus oder sehr weit distal in der Tibia ein 2. Steinmann-Nagel eingebracht.

Der Steinmann-Nagel in der distalen Tibia kann auch durch einen Halbring mit gespanntem Draht ersetzt werden ( $\bullet$ Abb. $\mathbf{3}$ ).

Die distale und proximale Komponente werden mit langen Kohlefaserstäben verbunden.

Mit dem Spanner für den Fixateur wird eine sanfte Distraktion ausgeübt. Es kann lateral und medial balanciert geschoben und gezogen werden. Durch diese ausbalancierte Distraktion gelingt es in den meisten Fällen, zu einer guten Reposition zu kommen.

Sollten weitere Repositionsmanöver notwendig sein, kann dies durch monokortikal aufsetzende Schanz'sche Schrauben von medial lateral oder ventral zusätzlich manipuliert werden. Von ventral erreicht man das dadurch, dass von lateralem zu medialem Rohr eine Brücke (u-förmiges Rohrsystem) gebildet wird ( $\bullet$ Abb. $\mathbf{3}$ ).

Das System hat viele Vorteile:

- Für die Marknagelung herrscht vollkommene Ruhe und sehr gute Stabilität. Dies schützt auch die Weichteile.

- Ein großer Vorteil ist, dass im Kniegelenk maximal gebeugt werden kann ( $\triangleright$ Abb. 1 und 3 ). Dadurch wird die Eintrittsstelle wesentlich leichter erreicht.

- Es wird Manpower gespart, weil niemand während der Operation halten muss.

Der Unterzeichner empfiehlt, dieses System nicht nur in Extremsituationen ( $\bullet$ Abb. $\mathbf{3}$ ) einzusetzen, sondern mög- 


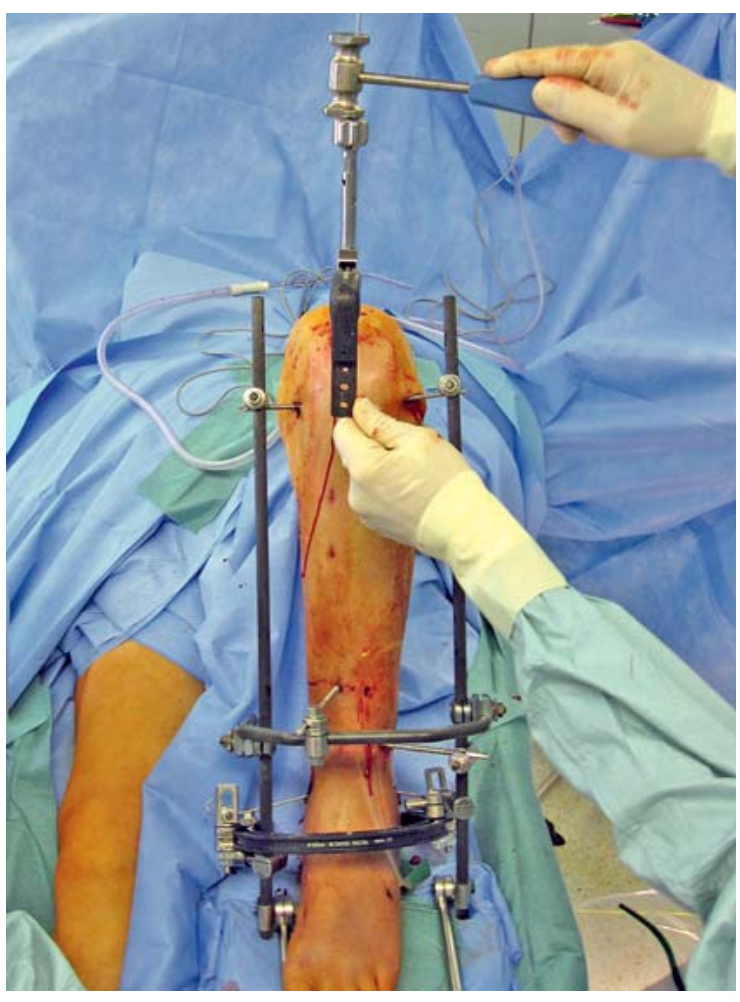

- Abb. 3 Bei einem „schwierigen“ Fall: sehr distale Fixation in der Tibia mit gespanntem Draht über Halbring und monokortikalen Schrauben zum Reponieren durch gezielten Druck, hier von ventral über eine U-förmige Brücke (U-förmiger Kohlefaserstab!). lichst oft. Allein dadurch ist man geschult und die Prozedur braucht nicht länger, als eine Unterschenkelfraktur in einem Extensionstisch zu lagern.

In der Klinik des Unterzeichners haben wir uns ein entsprechendes Set „Distraktionsrahmen“ zusammengestellt. Die Zusammensetzung kann beim Autor oder in der OPAbteilung der BG Unfallklinik Tübingen abgefragt werden.

\section{Merke}

Bitte senden Sie Ihre Tipps und Tricks ein, damit dies ein lebendiger Austausch wird und wir voneinander lernen können. Bitte an: op-journal@thieme.de oder Georg Thieme Verlag KG, OP-Journal, z. Hd. Frau Stickel, Rüdigerstraße 14, 70469 Stuttgart.

Korrespondenzadresse

Prof. Dr. Dankward Höntzsch

Tübingen

hoentzsch@t-online.de

Bibliografie

DOI https://doi.org/10.1055/s-0043-115015

OP-JOURNAL 2017; 33: 186-187 @ Georg Thieme Verlag KC Stuttgart · New York ISSN 0178-1715 